\title{
Vertical Axis Highway Wind Turbine including Solar Energy
}

\author{
Mr. Niraj J. Prajapati ${ }^{1}$, Mr. Jaydeep J. Patel ${ }^{2}$, Mr. Vedant U. Patel ${ }^{3}$, Mr. Azim F. Pathan ${ }^{4}$, \\ Prof. Tushar A. Patel ${ }^{5}$ \\ Electrical Engineering Students, Ranchhodlal Chhotalal Technical Institute, Ahmedabad, Gujarat, India ${ }^{1-4}$ \\ Professor in Electrical Engineering, Ranchhodlal Chhotalal Technical Institute, Ahmedabad, Gujarat, India ${ }^{5}$
}

\begin{abstract}
The objective of the project is to design a vertical axis highway wind turbine to recapture wind energy from the vehicles on the highway. Wind energy is considered the fastest growing clean energy source however; It is limited by variable natural wind. Highways can provide a considerable amount of wind to drive a turbine due to high vehicle traffic. The wind turbines will be placed on the medians therefore fluid flow from both sides of the highway will be considered in the design. Using all of the electrical energy, existing streetlights on the medians can be fitted with these wind turbines. Additionally, since the wind source will fluctuate, a storage system for the power generated will be designed to distribute and maintain a constant source of power. Ideally, the turbine can be used globally as an unlimited power source for streetlights and other public amenities. For this project we are looking for "Vertical Axis Wind Turbine". Mainly Savonius type of turbine can be used for this type of application as it collects wind from all kind direction.
\end{abstract}

Keywords: VAHWT, Solar, wind energy, Savonius.

\section{I.INTRODUCTION}

In a day-to-day life, the demand for the electricity is much higher than the production of electrical energy. One of the major problems ever since the natural resources are going to finish one day. Solar and wind both are renewable energy sources. Solar energy available begins of the day and the wind energy is maximum on the highway due to the speed of the vehicle. The motivation of this project contributes the global trend toward clean energy. The main motive behind this project is to design a vertical axis highway wind turbine which effectively uses the wind energy generated by the vehicle speed on the highway. So, the maximum wind energy can be extracted by the vertical axis highway wind turbine as compared to the horizontal axis wind turbine. savonius vertical axis wind turbine is used which is more efficient. This turbine works under all the environmental conditions and cyclones also. The arrangement of solar plats is placed on the top of the turbine to provide sufficient solar energy. The solar system generates electrical energy by sun radiation in day mode the generated electrical energy we can use street lighting, toll gates, etc.

\section{Global application}

The design can be used in any city around the world. It should be environmentally friendly. The world is now interesting in renewable sources of energy specially in wind energy.

The data of different 10 countries' average size of a new wind turbine installed in 2018 are shown in fig. 1. In 2018 India has installed new average 2,092 KW wind power plant and U.K. has installed a very large 3,950 KW wind turbine. As shown all other countries located on different continents are installed wind power plants on large scale. It shows the world is now attracting toward the wind energy. 
International Journal of Innovative Research in Electrical, Electronics, Instrumentation and Control Engineering

Vol. 9, Issue 7, July 2021

DOI 10.17148/IJIREEICE.2021.9720

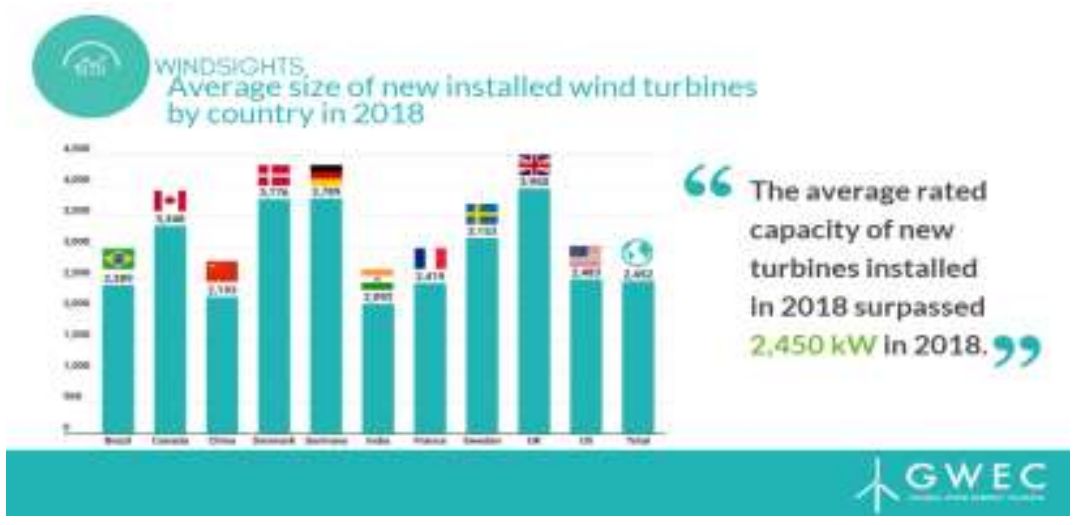

Fig. 1 The average rated capacity of new turbine installed in $2018^{[4]}$

\section{WORKING}

Fig. 2 Wind turbine block diagram

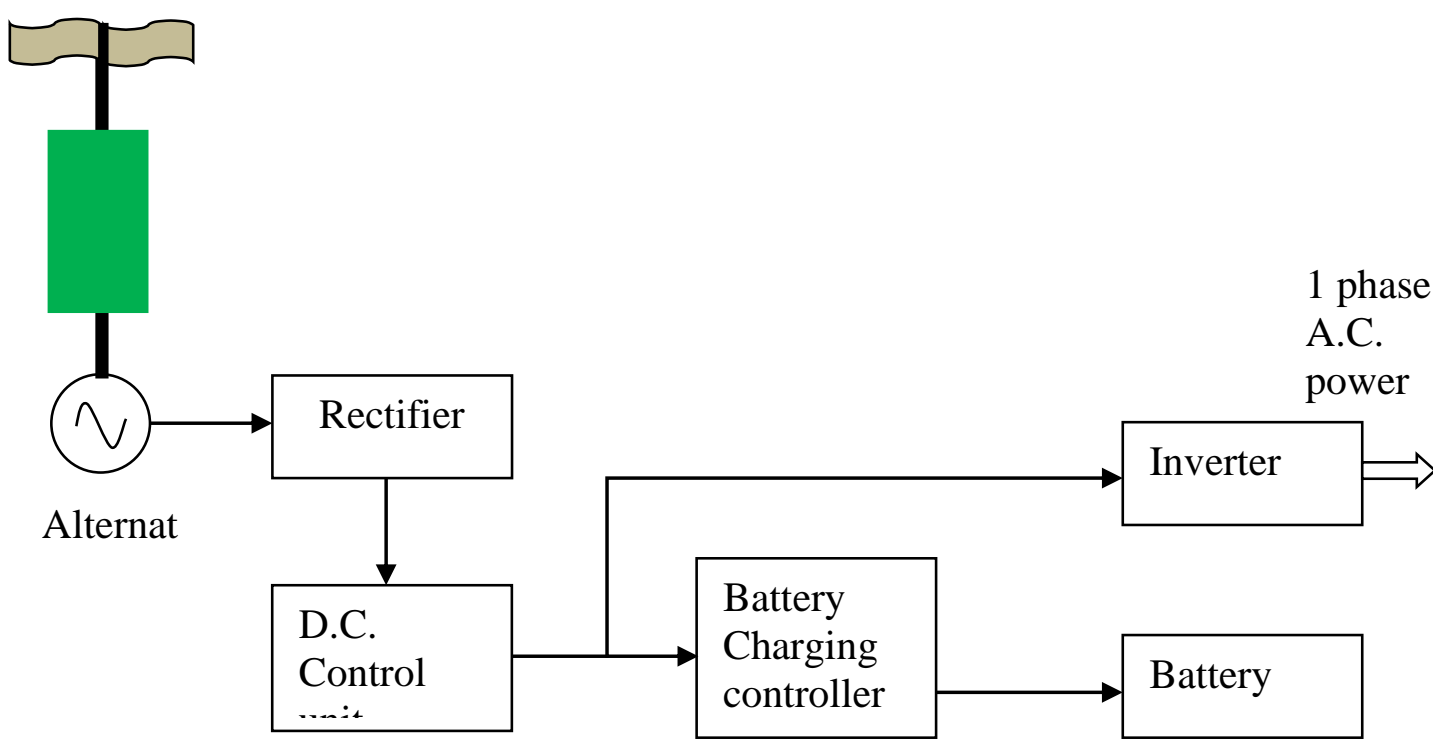

Whenever vehicle moves on both side of the highway divider then some pressurized air is produced due to the speed of vehicle. This pressurized air is strike on the blade of vertical axis wind turbine and turbine makes a rotation. The shaft of the vertical axis wind turbine is connected to alternator with the help of gear mechanism. The generated electricity is an alternating quantity; the output of the alternator is rectified by rectifier then filtered by filter circuit and makes required D.C. by using D.C. control unit and electrical energy stored in the battery. The output of D.C. control unit and battery converted in to A.C. by using Inverter and distributed to the domestic Sectors, street lighting etc. or fed into grid. 
International Journal of Innovative Research in Electrical, Electronics, Instrumentation and Control Engineering

Vol. 9, Issue 7, July 2021

DOI 10.17148/IJIREEICE.2021.9720

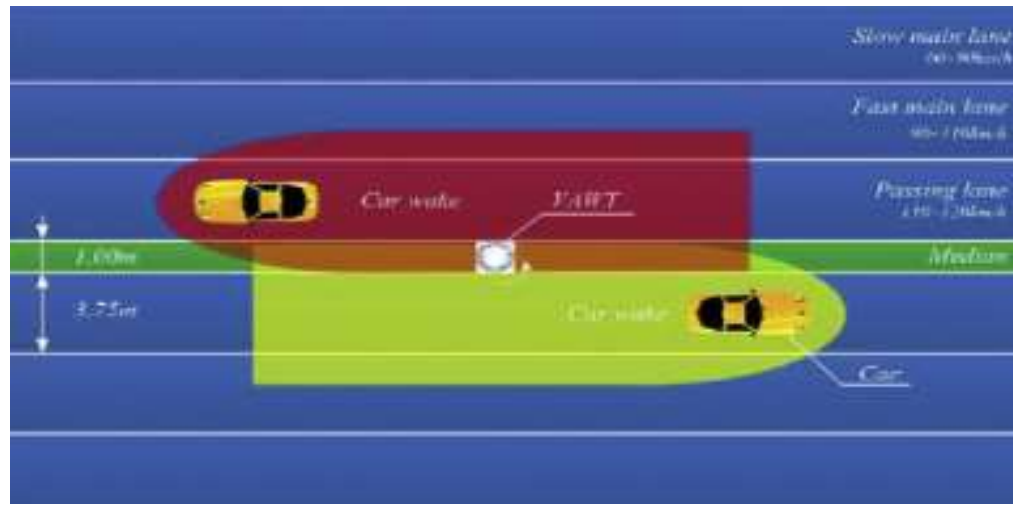

Fig. 3 Working of Vertical Axis Highway Wind Turbine ${ }^{[5]}$

The solar system is mounted on the top of the vertical axis wind turbine, the function of the solar system to generate the electricity for the highway street light. A solar cell or photovoltaic cell is an electrical device that converts the energy of light directly into electricity by the photovoltaic effect, which is the physical and chemical phenomenon. Solar cells are the building blocks of photovoltaic modules. The generated electricity is stored in the battery. The stored energy used as a street lighting.

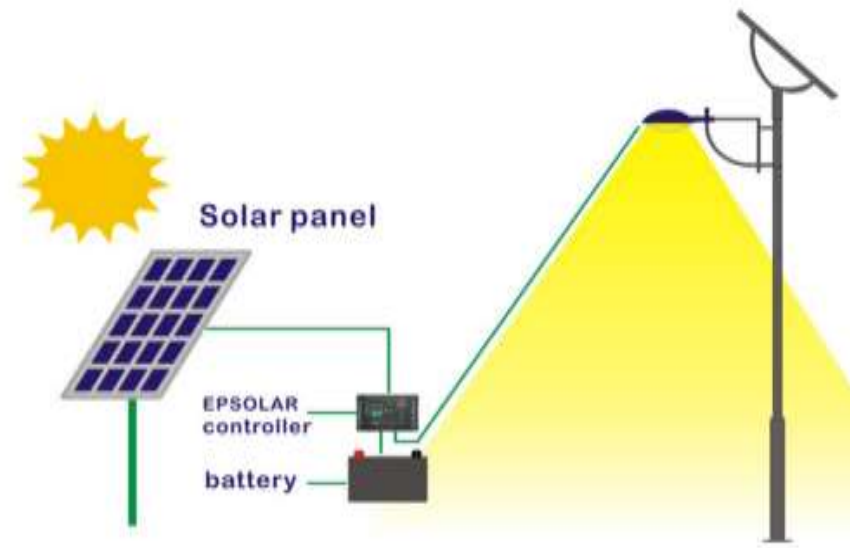

Fig. 4 Working of solar panel ${ }^{[6]}$

\section{LAYOUT}

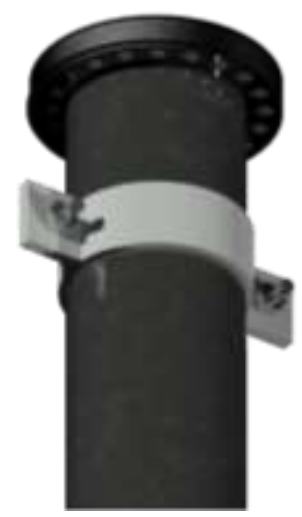

Fig. 5 Bearing of turbine 
International Journal of Innovative Research in Electrical, Electronics, Instrumentation and Control Engineering

Vol. 9, Issue 7, July 2021

DOI 10.17148/IJIREEICE.2021.9720

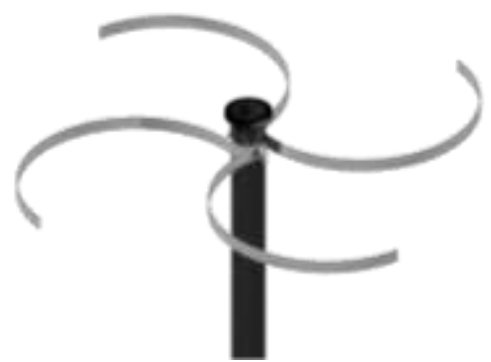

Fig. 6 Upper frame of blade

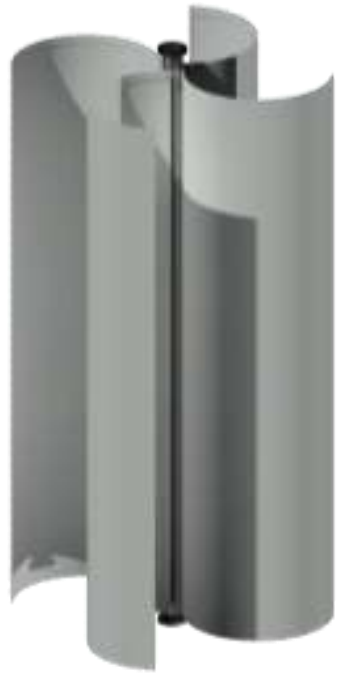

Fig. 7 Savonius type blade of VAHWT

The shaft of turbine is supported by two ball bearings provided at top and bottom of shaft. Metal frame of turbine is fabricated as shown in fig. 5 taking in consideration with direction of vehicle movement according to country. For the fabrication of turbine white acrylic sheet is used, due to its high durability and flexibility.

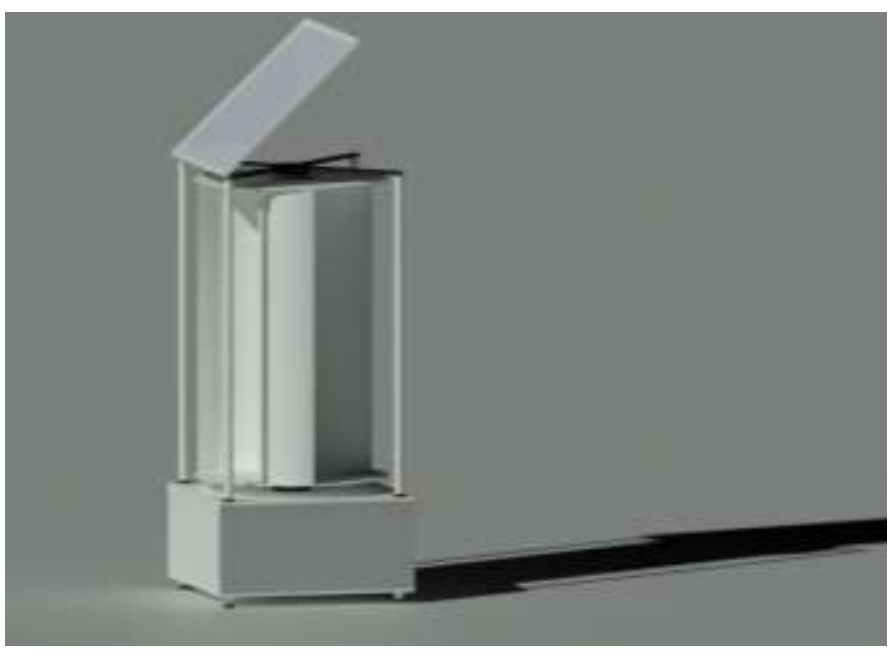

Fig. 8 Final Layout of VAHWT 
International Journal of Innovative Research in Electrical, Electronics, Instrumentation and Control Engineering

Vol. 9, Issue 7, July 2021

DOI 10.17148/IJIREEICE.2021.9720

\section{TESTING}

\section{Testing of Alternator}

We have measured the output of alternator which was balanced three phase voltage. We have used two nos. of multimeter which are connected across the R-Y phase and Y-B phase at first time. And then second time multimeters are connected across R-Y phase and B-R.

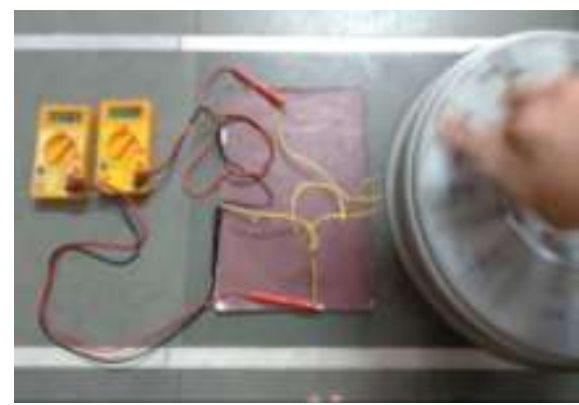

Fig. 9 Testing of Alternator

\section{Testing of Buck Converter}

The Buck converter provides constant 13 volt from variable de input supply. To verify the operation of buck converter we have tested buck converter by measuring output of converter at different input dc voltage.

TABLE I TESTING OF BUCK CONVERTER

Input D. C. volt $\left(V_{\text {in }}\right) \quad$ Output D.C. volt $\left(V_{o}\right)$

\begin{tabular}{|c|c|}
\hline 15 & 13 \\
\hline 20 & 13 \\
\hline 25 & 13 \\
\hline 30 & 13 \\
\hline
\end{tabular}

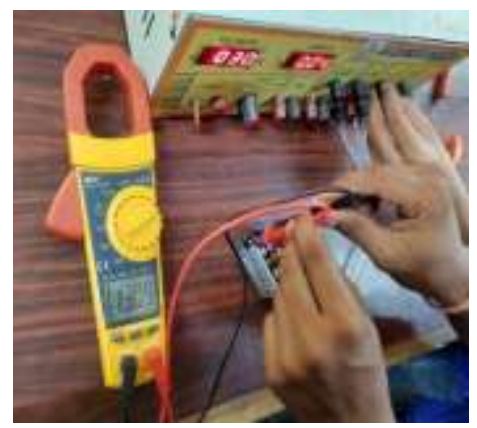

Fig. 10 Testing of Inverter

After testing of buck converter, we have found that it provides constant 13volt output at input range from 13-30 volt.

\section{Testing of Inverter}

The role of inverter in this project is to provide 220 volt A.C. at $50 \mathrm{~Hz}$ frequency at the input of $12 \mathrm{volt}$ D.C. The output of inverter is measured after applying the 12 volt D.C. input from variable dc source. We have obtained the 220 volt A.C. at input of 12 volt D.C. using variable power source. Then we have applied constant voltage to inverter by Buck 
International Journal of Innovative Research in Electrical, Electronics, Instrumentation and Control Engineering

Vol. 9, Issue 7, July 2021

DOI 10.17148/IJIREEICE.2021.9720

converter. At the input of buck converter, we have varied the D.C. voltage from 12 volt to 30 volt and we have obtained constant 220 Volt output from inverter

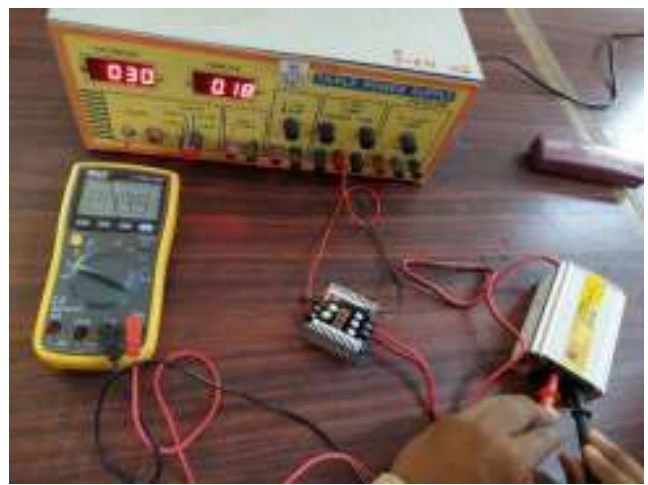

Fig. 11 Testing of Inverter

\section{Final Testing of VAHWT}

To test the VAHWT we have applied wind force using two handle blowers. Measured the final generated ac output which was $218.9 \mathrm{v}$ with connected lamp load.

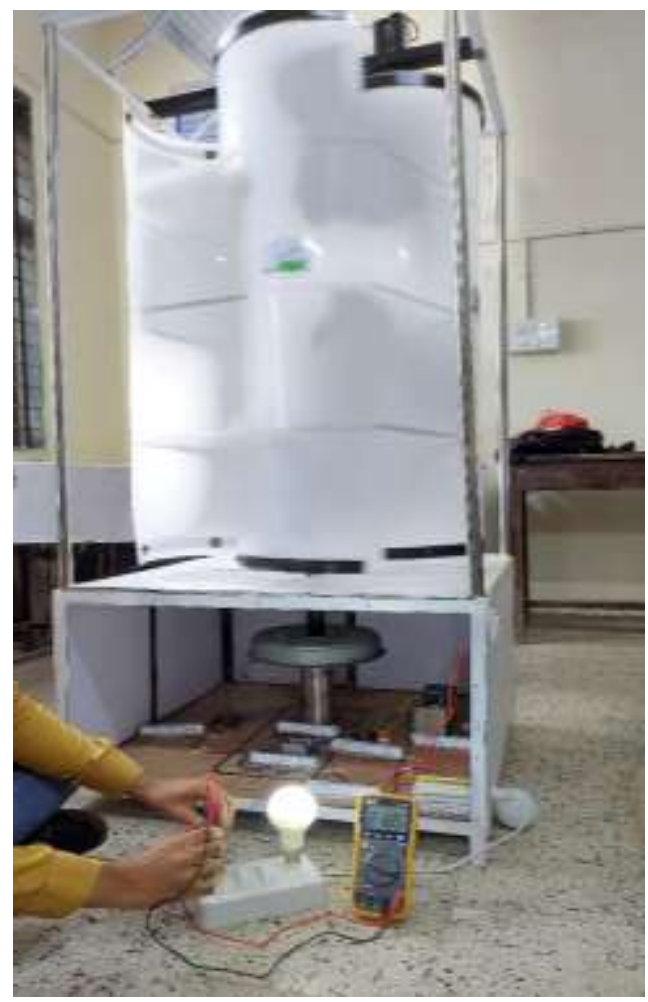

Fig. 12 Final testing of VAHWT

\section{CONCLUSION}

Conclusively, Using the collected data, a wind turbine is designed to be placed on the medians of the highway. Although one turbine may not provide adequate power generation, a collective of turbines on a long strip of highway has potential to generate a large amount of energy that can be used to power streetlights, other public amenities or even generate profits by selling the power back to the grid. This design concept is meant to be sustainable and 
International Journal of Innovative Research in

Electrical, Electronics, Instrumentation and Control Engineering

Vol. 9, Issue 7, July 2021

\section{DOI 10.17148/IJIREEICE.2021.9720}

environmentally friendly. Additionally, a wind turbine powered by artificial wind has a myriad of applications. The highway wind turbine can be used to provide power in any city around the globe where there is high vehicle traffic.

\section{ACKNOWLEDGEMENT}

We are pleased to present "Vertical Axis Highway Wind Turbine including Solar Energy" As our project and take this opportunity to express our profound to all those people who helped us in completion of this project. We would like to thank Prof. Tushar A. Patel for providing guidance and support, patience and faith.

\section{REFERENCES}

[1] Highway Helical Wind Turbine Project (Next Generation Highway's Potential For. (2012, November 20). (Department of Mechanical Engineering YCET Kollam. Kerala) Retrieved February 14, 2013, from Youtube.com: http://www.youtube.com/watch?v=8g5G0LXCNDM

[2] Global Statistics. (n.d.). Retrieved from Global Wind Energy Council: http://www.gwec.net/global-figures/wind-energy-global-status/

[3] Joe. (2007, April 11). Archinect. Retrieved March 15, 2013, from Arizona State University (Joe): http://archinect.com/blog/article/21451130/here-goes-please-comment

[4] GWEC Release side supply side data report 2018 from Global Wind Energy Council: https://gwec.net/newsroom/press-releases/

[5] Schemetic of the Highway wind turbine from Wen Lond Tian : https://www.researchgate.net/figure/Schematic-of-the-highway-windturbine_fig1_318812449

[6] Solar powered Led street light with auto intensity control circuit and working from ELEPROCUS: https://www.elprocus.com/solar-powered-ledstreet-light-control-circuit/ 